\title{
Report of an Excavation at the Oxbow Dam Site
}

\author{
by Robert W. Nero and Bruce A. Mccorquodale, \\ Saskatchewan Museum of Natural History
}

\section{INTRODUCTION}

On May 24, 1956, Lt. H. R. Inglis (then of Regina) while pursuing a private quest for archaeological sites in southeastern Saskatchewan came upon a large and recent cut in a river bank which at once caught his attention. Just below the dam on the Souris River near Oxbow, Saskatchewan, spring floods had cut into the east bank below a small terrace and washed away several yards of soil. Bones protruding from the bank at a depth of nine feet and several soil layers containing charcoal indicated an occupation site. Lt. Inglis made some minor tests of the soft layer, most of the site being hard clay, and shortly after brought the results of his tests to the Saskatchewan Museum of Natural History; he then expressed the belief that the Museum should conduct a serious examination of the site. Following the direction of the Museum staff, Lt. Inglis returned to the site and made an additional test, on the 12 th and 13 th of July. Lt. Inglis' subsequent observations suggested that the site might prove significant and since the terrace was being badly eroded it was decided to send a Museum grcup down at once for a more extensive test. The object was to secure only enough material to indicate the cultural nature of the site. The authors, assisted by Museum Assistant, Wolfram Niessen, worked at the site for two days, from noon on July 17 to noon on July 19. Although this report is based only on the results of work done by Lt. Inglis and the single test made by the Museum, it seems worthwhile, in view of the scarcity of publications on excavated sites in Saskatchewan, to document these investigations.

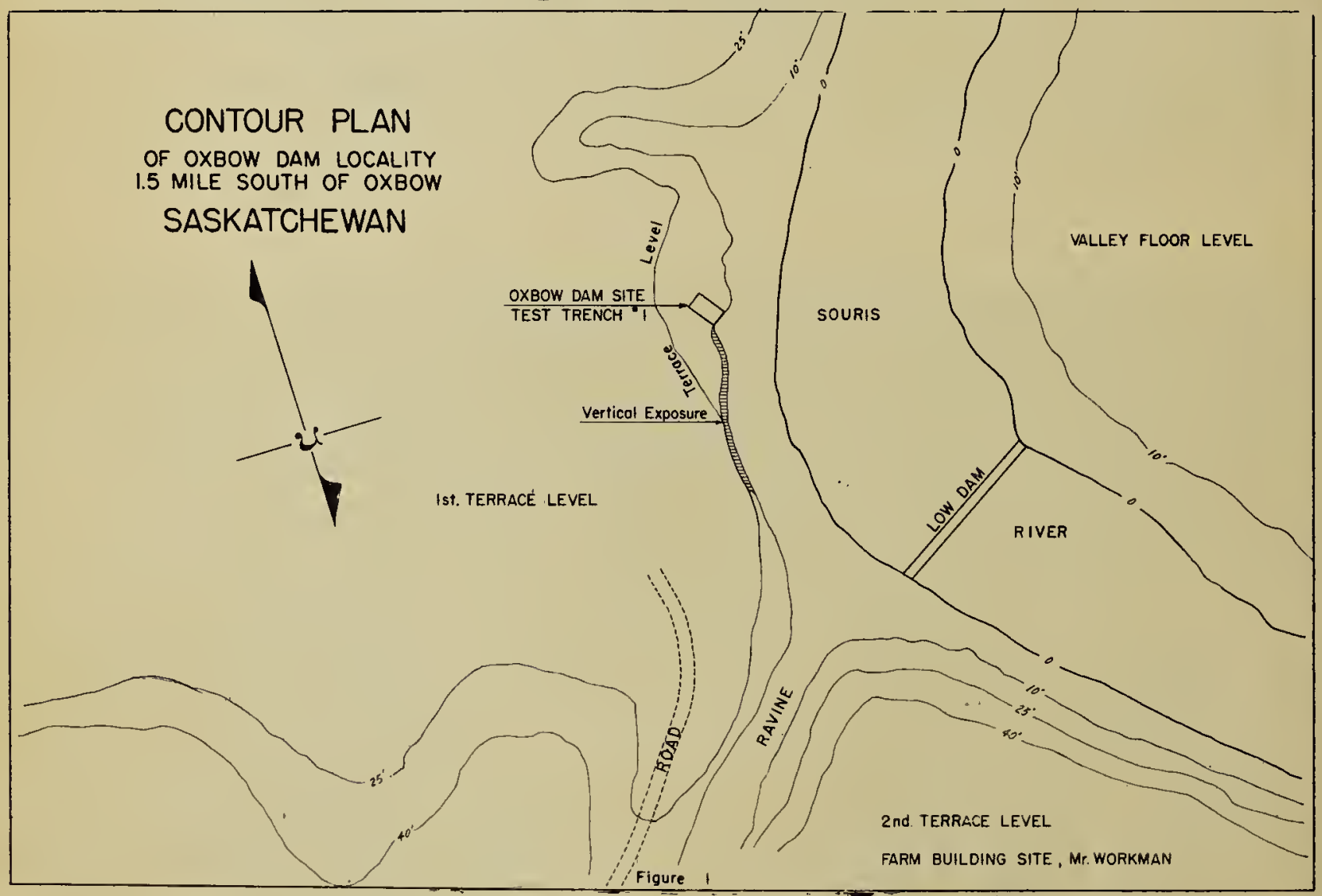

Fig. 1. Contour plan of Oxbow dam locality

\section{Description of Site}

The site lies on the east bank of a meander of the Souris River about one and one-half miles south of Oxbow, Saskatchewan, on the property of $\mathrm{Mr}$. J. A. Workman (land description-LSD 15, Sec. 14, Tsp. 3, R2, W 2nd). A low dam traversing the meander, 120 yards upstream (west- 


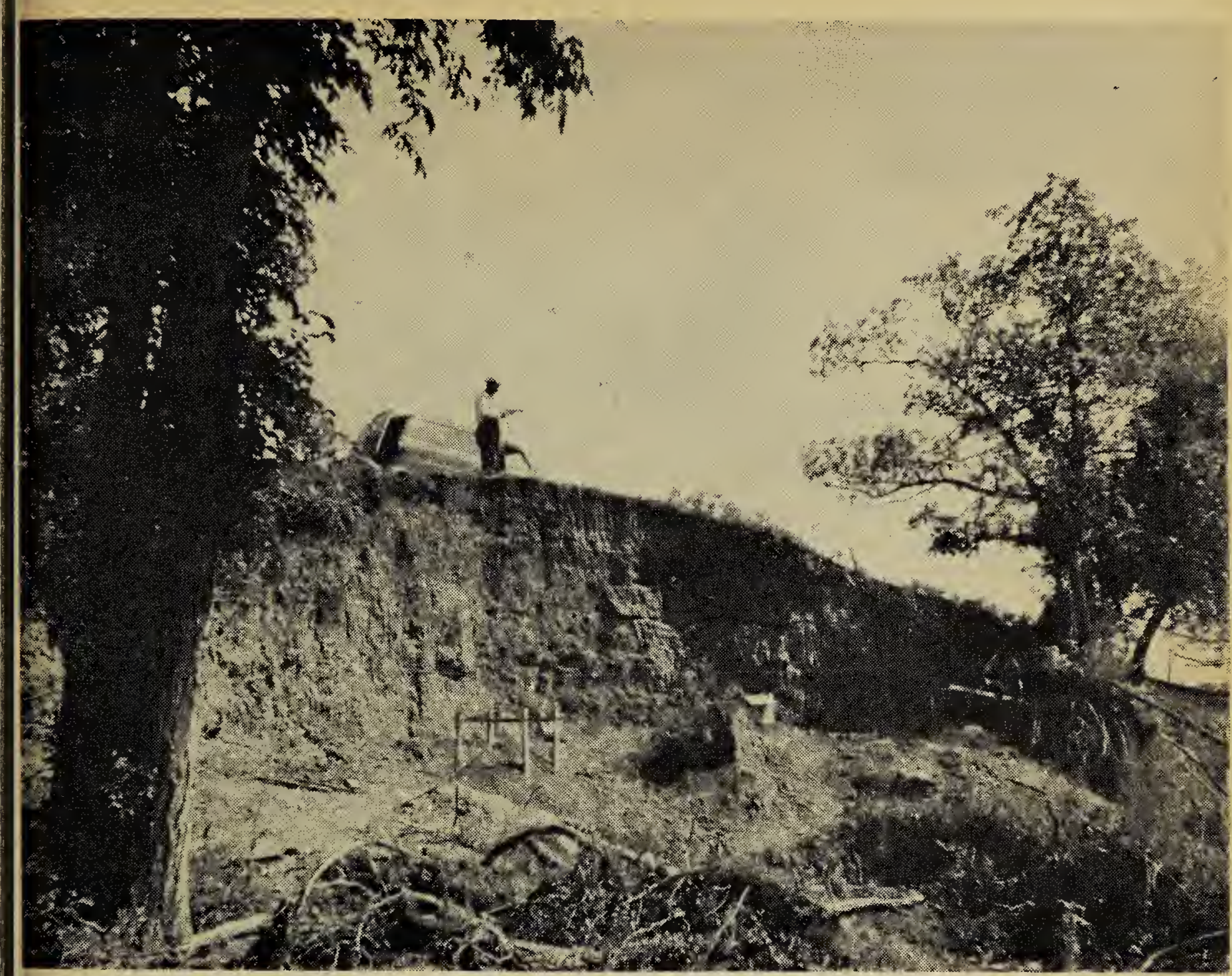

Photo by R. W. Nero

Fig. 2. View of vertical exposure and excavation at the Oxbow Dam Site.

ward), has provided the site with an appropriate name and a well defined lccation-marker. At the site the eastward trend of the stream changes rather abruptly to a southerly direction (see Figure 1). During flood seasons the volume of water flowing over the low dam is sufficient to cause undercutting on the east bank. On the curve of the meander the east bank rises to the level of the first terrace of the valley proper. Consequent slumping has resulted in creation of an extensive profile of the terrace in a vertical exposure which is over 75 feet in length and 22 feet in total height (see Figure 2).

The profile has revealed the fact that the sediments of the terrace are of alluvial origin. They consist chiefly of layers of partly stratified buff silts of the type commonly deposited by several dark silt zones impregnated with carbon and varying quantities of bone fragments (see Figure 3 ). The thickest and richest of these dark layers contained an obvious hearth site consisting of fine gray ash. It was from the exposed side of this hearth that Lt. Inglis reccvered most of his material and the Museum test pit was put down directly above this point. Cultural material was recovered only from this zone.

The authors wish to acknowledge the kindness of $\mathrm{Mr}$. J. A. Workman in permitting access to the site, and in other considerations. Only through the cooperation of landowners can we continue these studies which help reveal the history of man. We wish also to thank Fred G. Bard, Museum Director, for his interest in supporting this research.

\section{Results Obtained by Inglis}

On the 24th of May when Inglis first visited the site the hearth was quite evident and more prominent than later. His sketch of the whole exposure, made on that date at the site, indicates the presence of what appeared to be the partial skeleton of a bison in the central area of the zone containing the hearth. The latter was drawn as a long lozengeshaped "firebed" by Inglis. 

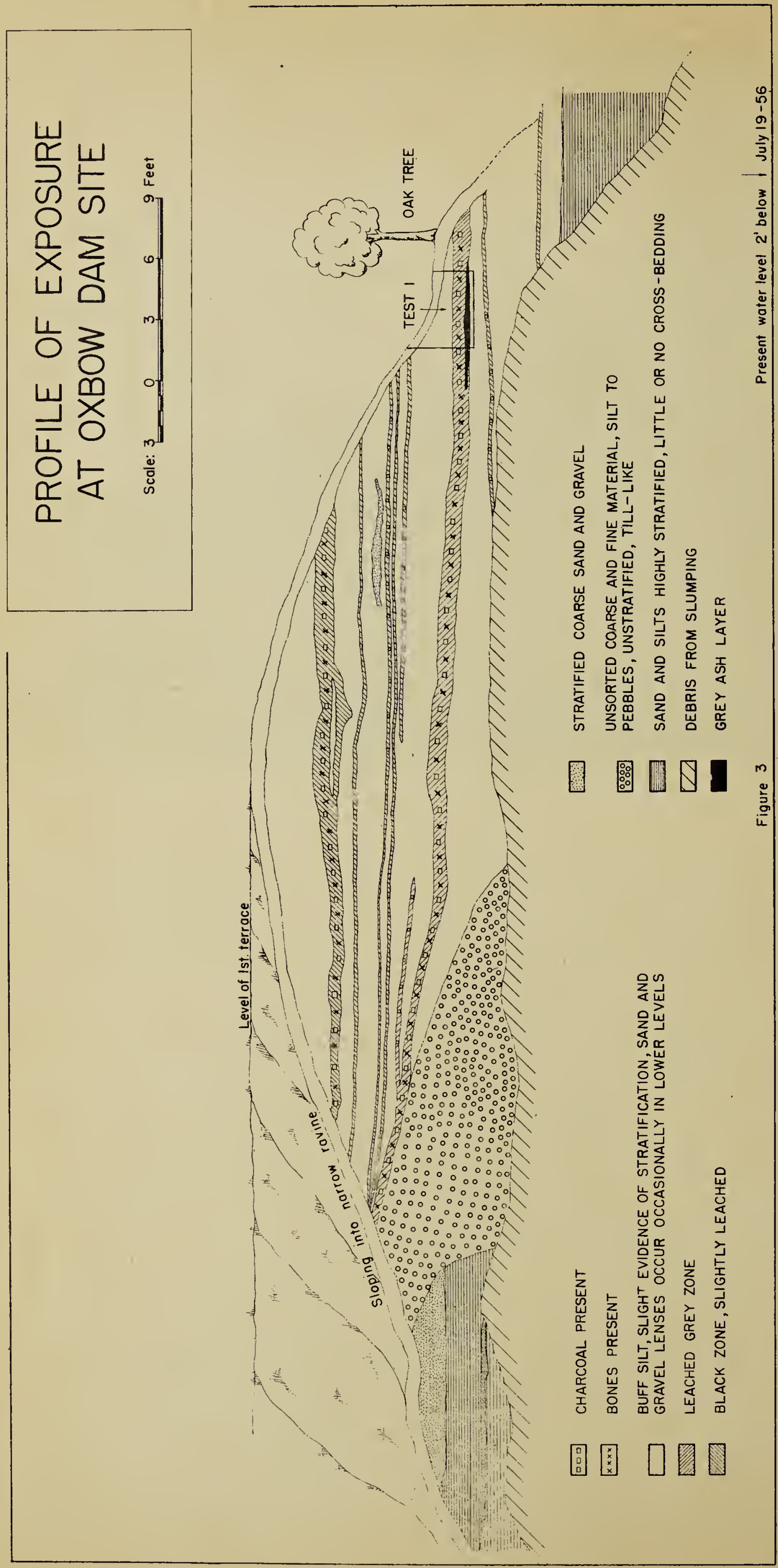
On the 12th and 13th of July, Inglis probed horizontally into the soft layer of ash to a depth of from 18 to 24 inches, encountering a "scrap pile?" of bone and stone. His sketches show the position of two large granitic stones (about six inches in diameter) which he correctly designated as anvils, a ". . . top layer thick with small flints-some bone fragmentscharcoal and ashes," several large flint "scraps" or flakes and large quantities of bone fragments (see below). One of the anvils was in the hearth but the other was off to one side along with most of the bone material and the large pieces of flint. The anvil in the hearth was surrounded by many small flint flakes, a clear indication that it had been used as an anvil where it was found. Inglis discovered in addition the tip of a projectile point (Fig. 5D), two sidescrapers, a finely retouched flake knife, and two flakes which appear to have been used as knives.

\section{RESULTS OF MUSEUM TEST}

Following our arrival at the site on July 17 we made an attempt to test the debris at the base of exposure. A great deal of earth had slumped from the verticle wall and formed a bank sloping steeply into the river. Some two and one-half hours were spent breaking up the hard lumps of clay and screening all available loose dirt in the hopes of recovering material which would otherwise be lost and which might indicate the nature of the site. This effort proved nearly fruitless and impractical owing to the vast amount of sterile earth involved. The remainder of the afternoon was spent screening the earth which had been dug out of the hearth area by Lt. Inglis and some unknown persons. This resulted in the recovery of a projectile point base (Fig. 5,E).

On July 18th we opened a small test pit above the hearth area, partly because this seemed likely to be the most revealing spot and also because owing to the sharp slope of the surface, a minimum amount of earth lay above. The total excavation consisted of a pit four by eight and onehalf feet and four feet deep. Profile sketches (see Figure 4) were made throughout the excavation. Initially, all of the earth involved was carefully screened and the screenings washed in the river and closely in-

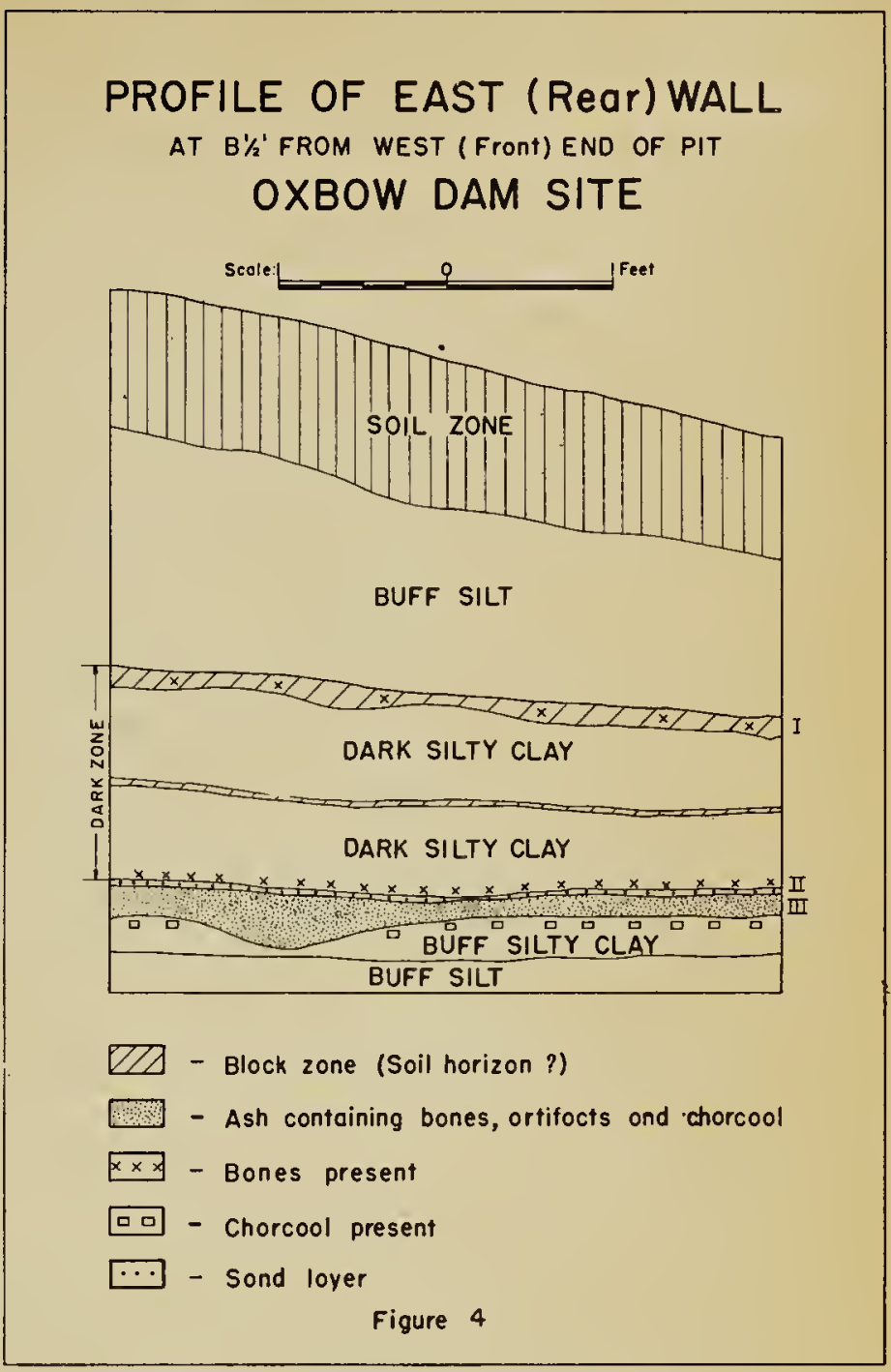

Fig. 4. Profile of east rear wall.

spected. Since no cultural articles were recovered from the uppermost layers, these were later sacrificed. All of the earth for six inches above the hearth, as well as that for three inches below, was carefully screened. The hearth layer itself was worked completely with a trowel, nearly all of 26 artifacts and 471 flint flakes which were found being located in situ and in direct association with the hearth. About seven feet back from the face of the exposure a small depression, about two feet by one foot and five inches deep was found at the level of the hearth. This was filled with solid ash, some of which extended beyond the depression and overlay the hearth layer. No artifacts were found within this pit.

\section{ARTIFACTS}

The more significant artifacts which were found are illustrated in Figure 5. The projectile points are all small and side-notched. Two basal fragments of a point which was found by us fitted a piece found by Inglis (Fig. 5,D). (The smallest piece was found among the collected flakes after the figure had been prepared.) This point appears to have fragment- 

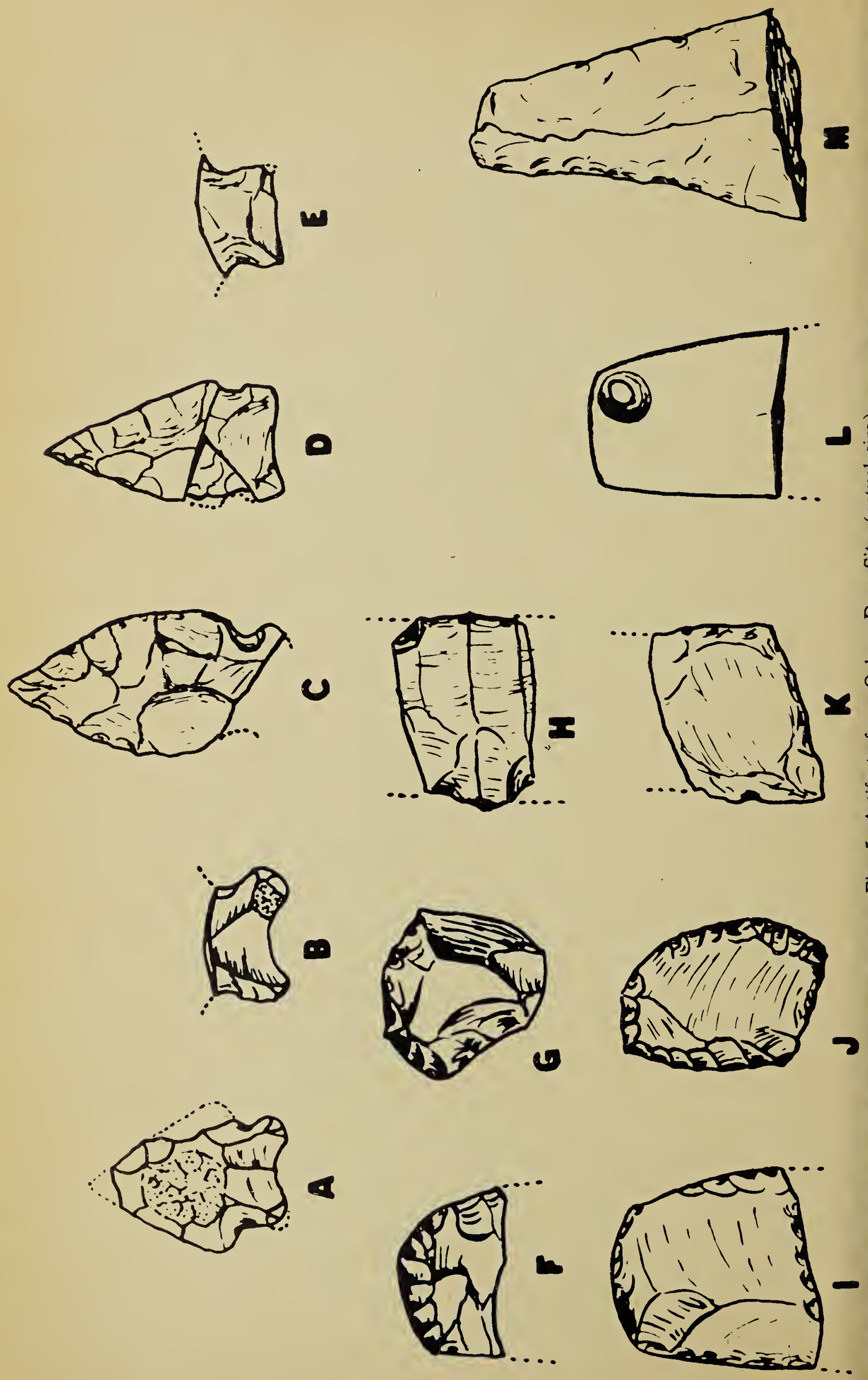
ed as a result of being heated by fire. Point A is badly fire-burned chalcedony; $\mathrm{B}$ is of fine red chert; C, creamy white chert; $\mathrm{D}$, also badly fire-burned, grey chert; $\mathrm{E}$ is of brown chalcedony (Knife River flint). Three of the projectile points show slight signs of grinding in the notch area only (Fig. 5,A,C,D). Measurable and estimated widths between the notches ranged from 12.0 to $13.5 \mathrm{~mm}$. The thickness at the level of the notches ranged from four to six $\mathrm{mm}$. Note the definite thinning of the base by the removal of one or more large flakes. Scrapers F, G, and J are of brown chalcedony; $\mathrm{F}$ has a slightly worn distal edge; I is of grey, banded chert - the distal cutting edge has been worn quite smooth, but the edges on both sides of the scraper are sharp." Note the retouching along the edge of the break at the base.

Microscopic examination (10X) of the worn edge of the above scraper revealed fine irregularly-placed striations arranged cross-wise to the edge. These are prominent enough to be detected by scraping with the edge of a fingernail. It would appear that this artifact was used on a tough, irregular surface in a chisel-like pushing movement while held at an angle of about 30 degrees above the horizontal. Features such as worn or ground edges which reveal or suggest utilization may be of archaeological significance. The worn edge described above is unlike most worn edges which we have seen on scraper bits, but at the moment it is difficult to imagine what use this tool may have seen.

Two blade fragments were also cound $(H, K) . H$ is made of brown chalcedony and shows fine horizontal laking technique on both sides; $\mathrm{K}$ is mottled pinkish chert fragment of incertain form. A portion of a shell bendent or gorget (L) has a hole three $\mathrm{nm}$. wide which has been drilled irom both sides. In the illustration the inner surface of the shell-the "pearly" side-is shown. The inerior of the hole, on the surace illustrated, and the entire reverse furface of the shell bear a thin ayer of red pigment. This fragmenary shell artifact is rounded and lighly polished on the edges. It has maximum thickness of six $\mathrm{mm}$. A ềry small $\mathrm{piece}$ of similarly rainted shell which was also found may be from the edge of this artifact but it is much thinner. $M$ is a crude flake knife of white chert. The left edge has been retouched from both faces. Additional artifacts which were found but which are not shown include 10 flakes which show retouching and three chert, core-like fragments which appear to be worked. One fragment of heavy long-bone (probably bison) shows signs of wear on one end and may have been used as a tool.

It is interesting to note that although eight of the 22 stone artifacts $(36 \%)$ which were found are made of chalcedony, only nine out of 460 waste flakes $(2 \%)$ were chalcedony, 395 being chert $(.85 \%)$. This vast difference in frequency of occurrence suggests that although chalcedony was not readily obtainable it was in great demand. The fact that the nine chips which were found are all small is further evidence and suggests that maximum use was made of this material. This seems strange to us considering the present widespread distribution of chalcedony artifacts cn the surface in southern Saskatchewan, and the nearness of the site to chalcedony sources in North Dakota.

Another distinct stone material which was used is a dull, opaque fused shale which is believed to criginate from a shale stratum which overlies a prominent coal layer in the "Ravenscrag" formation of the southeastern portion of the province. This shale has been baked to a hard flinty nature in localities where the underlying coal seam has been burned. There is some evidence of quarrying of the fused shale at exposures near Estevan. Fifty-six flakes and two of the artifacts were composed of material of this nature.

\section{DATING AND COMPARISON WITH OTHER SITES}

Charcoal samples which were collected directly from the heavy bed of ash in the hearth have been radiocarbon dated by Professor K. J. McCallum, University of Saskatchewan, Chemistry Department. Two different runs were made which yielded dates of $5100 \pm 210$ years and $5350 \pm 250$ years. Mean values for these two measurements were calculated to be $5200 \pm 130$ years. (Personal correspondence, 1958). This is presently the oldest date for a culture-bearing 
deposit in Saskatchewan and one of the oldest in the Northern Plains.

There is some resemblance of artifacts from the Oxbow Dam Site to material, which we have examined, from lower levels at the Long Creek Site (Wettlaufer, 1957), especially level No. 8, which has been radiocarbon dated by Professor McCallum at $4650 \pm 150$ years. Although not strikingly apparent, some similarities were noted in the size, shape, and flaking technique of certain points; worked shell, similarly worked bone. tools and other.items occurred in both samples. On this basis one would judge the Oxbow Dam Site material to be related and possibly antecedent to Long Creek Site, level No. 8. Support for the possibility of relationships is also suggested by the fact that the two sites are located 40 miles apart in valleys of the same drainage system. A more complete comparison will appear in the final report of the Long Creek Site (Wettlaufer, personal communication).

No relationship to any levels at the Mortlach Site (Wettlaufer, 1955) could be determined and judging by the $\mathrm{C}-14$ dates assigned to Mortlach the Oxbow Dam Site material is from an older time period.

\section{FAUNAL REMAINS}

The bone material recovered by Lt. Inglis for the most part consisted of vertebral fragments, phalanges, carpals and teeth of two or more individual bison (Bison) including at least one immature individual and one medium-to-large bison which was probably a male. In addition, Inglis collected skeletal parts of a large canid, including the left dentary, portion of the left humerus and fragments of four metapodials. On the basis of size, proportion and other characteristics of the ramus and dentition this canid has been tentatively identified as a medium-sized wolf (Canis lupus). We must point out, however, that the distinction would be slight between a true wolf and a domesticated canid derived partly from wolf stock. Therefore, identification of these canid remains must be made with reservations. All of the above-mentioned bone material was collected by Inglis either from the hearth or from the same layer.
All of the bones, whole and frag mentary, that were recovered as result of the Museum test wer catalogued as to level and retaine for detailed examination. Three bone producing levels were recognized is the test pit. (See Fig 4.) The upper most (zone 1 ) consisted of a thi silty layer, 2 inches thick, lying 1 inches above the hearth. The lowe two zones (zones II and III respec tively) consisted of a sand layer, inch thick, and the hearth laye immediately underlying the sane layer. The bone fragments containe in zone II were observed to b lying flat in a horizontal plane nea the middle of the zone, in som areas in direct contact with the ash Because there was little evidence o vertical separation between thes lower zones, and because both wer included in the same black layer, w can reasonably assume that these tw levels were coeval, and may be con sidered as one. However, in keepin with the principles of a factual pres entation we have separated them is the following summary.

Zone I yielded two phalanges o medium to small bison plus a pha lange and fragment of the radius 0 a large bison. Additional specimen were a fragment of proximal met atarsal epiphysis and the ectocunei form (tarsal bone) of an ungulat tentatively identified as an El (Cervus canadensis).

Zone II produced the right mand ible of a Kit Fox (Vulpes velox) an a few nondescript fragments of biso phalanges and metacarpals.

Zone III yielded a more extensiv array of bison bones and teeth in cluding four fragments of metacar pals and metatarsals, two phalange: five carpals, four vertebral fragment and one mandible. Comparisons $c$ sizes revealed that at least one large one medium-to-large and one med ium-to-small bison are represente in this collection. In addition to th bison remains a partial skeleton of frog and a partial left tibia of a cani were recovered. The canid tibia i tentatively identified on the basis $c$ conformable features, sizes and pro portions as that of a Coyote (Cani latrans). Another specimen is a frag ment of a left tibia of a small fox sized carnivore. Innumerable sma: pieces of bone, burned and unburnec 
plus a substantial number of fragments of clam shell were recovered from the ash of the hearth.

The species identified from these faunistic remains are indicative of a Plains habitat and Transition Life Zone conditions. Undoubtedly, the general area was not much different from what can be seen there today, although there were probably fewer trees. The Kit Fox record is of considerable importance since so few records of this formerly rather abundant species are available for Saskatchewan (Symons, 1956). This record indicates the occurrence of this prairie species at an early period and extends our knowledge of its former range.

\section{TABLE OF FAUNA (representative of all discovered remains)}

\begin{tabular}{l|c|c|c|c}
\hline \multicolumn{1}{c|}{ Animal represented } & $\begin{array}{c}\text { No. of } \\
\text { individuals }\end{array}$ & Recovered by & Zone or layer \\
\hline Bison (large) & 2 (?) & Museum & Zones I \& III \\
Bison (Medium to large) & 1 (?) & Museum \& Inglis & Zones II \& III \\
Bison (Small to medium) & 2 (?) & Museum \& Inglis & Zones I, II \& III \\
Bison (Immature) & 1 & Museum & Zone III \\
Elk (Cervus canaderis) (?) & 1 & Museum & Zone I \\
Kit Fox (Vulpes velox) & 1 & Museum & Zone II \\
Wolf (Canis lupus) (?) & 1 & Inglis & Adjacent to Zone III \\
Coyote (Canis latrans) (?) & 1 & Museum & Zone III \\
Carnivore (fox-sized) & 1 & Museum & Zone III \\
Frog (Rana) (?) & 1 & Several & Museum & Zone III \\
Clams (Pelecypods) & &
\end{tabular}

\section{GEOLOGICAL SIGNIFICANCE}

In the immediate locality of the site the stream meander follows the north side of a broad valley-flat of the flood plain variety. This valleyflat is approximately one-quarter to one-half mile in width and forms the floor of the Souris River Valley. It is bounded by steep slopes rising to the level of the bed of glacial Lake Souris. At least three terraces are discernible on the valley slopes. The lowest and youngest of these is exposed in the profile associated with the hearth site (see Fig. 2).

The top of this terrace lies approximately 15 feet above the mean floor of the valley proper and on the date of excavation by the Museum was 27.5 feet above the surface of the water in the channel. Upstream (westward) from the site all traces of this terrace have obviously been removed by undercutting of the stream as indicated by the proximal position of its channel to the uprise of the higher second terrace. Eastward (downstream), however, the first terrace was observed 'to con- tinue for a distance of at least onehalf mile as a well-defined valley feature distinguished by its shelf-like structure and continuously flat and and even upper surface. The major part of the sedimentary structure of the terrace has already been described as partly stratified flood plain silts. Under these silts the profile reveals the uppermost part of a series of well-stratified sediments comprising fine $\mathrm{s} a \mathrm{nds}$ and $\mathrm{gravels}$ which appear to be of fluvial origin (see Fig. 3). These differences in the nature and origin of the sediments imply changes in depositional conditions. Near the left terminus of the exposure an intrusive zone of unsorted till-like material may represent slumping of the adjacent wall of the second terrace.

In considering a possible sequence of events which would explain the topographical and sedimentary features of the lower part of the valley it seems obvious that in early postLake Souris time the valley had been down-cut to a level well below the present valley floor. Several features of the valley suggest the presence 
of a substantial depth of fill in the original post-glacial drainage channel. Although the nature of the major portion of these buried sediments is unknown it is qu ite conceivable that the stratified fluvial sediments of the lowest part of the profile (Fig. 3 ) constitute part of this series. The presence of this well-stratified coarser material indicates that the valley may have contained a stream of much greater magnitude than at present. The implication is that a rainy climate would be necessary to provide such a great volume of stream flow unless the valley was still active as a glacial spillway. The profile reveals that the change from fluvial sediments to flood plain silts is so abrupt as to suggest sudden changes in depositional conditions. Perhaps this has considerable climatological significance. The presence of broad black zones (thick soil profiles), small concentrations of white mineral salts in the silt, leaching of only minor extent and the relative lack of coarse sediments and definite stratification suggest that arid conditions prevailed during the deposition cycle represented by the major portion of the terrace. Fortunately the time of the commencement of this cycle may be approximated owing to the fact that the hearth site, dated at $5200+130$ years, lies only five feet above the base of the buff silt zones.

Postulations as to events responsible for the creation of the terrace are more difficult. Obviously, depositional conditions of a minor nature prevailed in the valley during the formation of the buff silt-zone. A subsequent erosional cycle is necessary to explain the reduction of the valley floor to a depth in excess of 15 feet, creating the lowest terrace Theorizing as to reasons for thi change, we must consider such fac tcr 3 as an increase in stream gradien a drcp in base level, a break-throug down-stream, a change in sedimen tary load of stream water or increas in vclume of water carried by th valley. The adaptability of the fourt and fifth factors, with emphasis o. the fifth, may be a pertinent aspect i acceptance of any theory. Any in crease in volume of water suggest: of course, a climatic change to con ditions of relatively higher precipita tion.

In order to gain a greater ap preciation of the significance of th depositional sequence we must con sider. the conditions which are pre vailing at present. The present-da rate of precipitation is so low in th upper region of the Souris drainag system that the meander channel, $\mathrm{i}$ the region of the site, is large enoug to contain all but the severest $c$ seasonal floods. Without a substan tiating study of the valley sediment we can state only that deposition $c$ the flocd plain variety appears $t$ be taking place at a very slow rat A brief perusal of the climatologic: studies of other authors (Antev 1955 ; etc.) tends to indicate th probability of a direct correlatio with the climatic history evidence in more southerly areas of th continent.

\section{LITERATURE CITED}

ANTEVS E. 1955. Geolcgic Climatic Dati1 in the West. American Antiquity, 20:31 335.

SYMONS, R. D. 1956. Where is the Kit Fo Blue Jay. 14: 63-65.

WETTLAUFER, B. 1955. The Mortlach Sit Anthropological Series No. 1. Departme of Natural Resources, Regina.

1957. The Long Creek Site. Blue Jay, 1 167-169.

\title{
The Role of the Archaeological Society
}

\author{
by Henry W. Hamilton, Secretary. Missouri Archaeological Society, \\ Marshall, Mo.
}

\section{INTRODUCTION}

Henry W. Hamilton is a business man who has long been an amateur archaeologist and an active member of the Missouri Archaeological Society. He is secretary of this organization which is recognized as one of the most successful societies of its kind. Mr. Hamilton is also a membe of the National Committee for the Re covery of Archaeological Remains. $F$. has kindly consented to write th article especially for the Blue Jay, recognition of our own interest an archaeological programme at tl 